\title{
El protagonismo político de la CNT en los ayuntamientos catalanes (1936-1939). El Vallès Occidental
}

\author{
Matías Vargas Puga
}

\begin{abstract}
RESUMEN
ABSTRACT

El estallido de la Guerra Civil en Cataluña trajo consigo la colaboración de todas las organizaciones que se oponían a los rebeldes y el nacimiento de un nuevo régimen en el que la Confederación Nacional del Trabajo dejó de ser oposición y pasó a ser parte integrante del nuevo poder político. Los sindicatos inspirados por el anarquismo revolucionario formaron parte de los gobiernos unitarios de los

Ayuntamientos hasta el final del conflicto bélico.

The Guerra's Civilian explosion in Catalonia brought get the collaboration of all the organizations that you/they were opposed to the rebels and the birth of a new regime in which the National Confederation of the Work stopped to be opposition and it became integral part of the new political power. The unions inspired by the revolutionary anarchism were the unitary governments 'of the City councils part until the end of the warlike conflict.
\end{abstract}

A pesar del tiempo transcurrido diesde el final de la contienda, es evidente que aún hay algunas lagunas profundas en la historiografía sobre el devenir del movimiento libertario español durante la misma. Una de ellas es la que tiene como centro de atención el poder jurídico-político-administrativo ejercido por el movimiento en los diferentes Gobiernos y Administraciones Públicas.

Aquí haremos breve referencia al poder político que ejercieron las $\mathrm{Fe}$ deraciones Locales de Sindicatos en los municipios catalanes; en concreto, a los veintidós que conformaban la comarca del Vallès Occidental, encabezados por Sabadell y Terrassa. Una comarca que cuenta al comienzo 
de la contienda con una población de ciento cuarenta y cinco mil habitantes, que está desarrollada en industria y servicios y que es limítrofe de Barcelona ciudad. Una comarca en la que grupos de militantes ya protagonizaron acciones armadas insurreccionales - de "gimnasia revolucionaria»-en 1932 y $1933 .$.

\section{UNA CONFEDERACIÓN QUE DIJO NO A UNA MILITANCIA ARMADA}

Dos meses y medio antes de que la reacción burguesa intente el golpe de Estado y se origine la guerra civil (no entre territorios, sino entre los ciudadanos de todos y cada uno de los territorios comprendidos dentro de las fronteras españolas), el movimiento libertario español (e internacional) tiene puesta su mirada y su corazón - porque ningún historiador que se acerque al conocimiento del movimiento libertario de aquella época podrá entender nada del mismo si no tiene en cuenta el componente psicológico fundamental que desarrolló en personas y grupos su acercamiento al Ideal- en el encuentro, el reencuentro, de Zaragoza. Allí se está celebrando una fiesta, una gran fiesta, más que un Congreso frío y racional. Se trata de una fiesta de los militantes que llevan muchos años ya sintiendo - porque de sentimientos se trata - que cada día está más próxima la hora de realizar el gran "sueño» de la revolución social. Hay que celebrar el resurgimiento de la Confederación, el final de la división, las perspectivas que se abren en el horizonte... Allí se encuentran gentes de todas las tendencias y grupos, todos unidos por la alegría. Todos son «compañeros» de una gran familia...

Sin embargo, unos pocos quieren aguar la fiesta introduciendo el tema de la defensa confederal, la necesidad de contar con una fuerza paramilitar cada vez mejor pertrechada y organizada. Algo típico de la época en los grupos políticos de distinto signo. Desde hacía un tiempo se sabía de la existencia de "ruido de sables» en los cuarteles y desde 1934 el temor al enemigo común - el fascismo- había ido progresivamente posibilitando el acercamiento de toda la izquierda, incluida la libertaria, en torno a un objetivo: frenarlo. Frenar a la reacción del capital ante el avance imparable del movimiento obrero revolucionario.

Se desatendió un asunto tan importante y ello tendría repercusiones directas en muchos de los militantes que acudieron a Zaragoza. Es más que seguro que muchos de ellos se acordarían de Joan García Oliver -el líder carismático y experimentado en las acciones de la denominada "gimnasia revolucionaria», el futuro partidario de «ir a por el todo", el que aboga en ese histórico momento a favor de una militancia armada parale- 
la, de la creación y extensión de los Cuadros de Defensa Confederalcuando, al comenzar el alzamiento reaccionario, comprendieron que sus vidas estaban en juego, que ésa era la triste realidad y que muy poco podían hacer para salvarla... Muchos pensarían entonces que una cosa era realizar una huelga, un sabotaje o una manifestación y otra muy diferente luchar, textualmente, contra el enemigo de la revolución libertaria...Pero ya era muy tarde para ellos y para el anarquismo español: era el principio del fin, a pesar de varias décadas de sacrificios de todo tipo, a pesar de haber tenido tantos ejemplos de fracasos, de la muerte de muchos «mártires" del ldeal...

En la ciudad de Barcelona y cercanías, era distinto. Los hombres experimentados en jugarse la vida durante muchos años en apoyo a "la causa" confederal y anarquista eran los que ahora se encontraban situados en los comités más importantes... Ellos no estaban dispuestos a ser fácil presa de la reacción... Pero ya era muy tarde para cualquier otra opción que no fuese la de sumar voluntades y energías al resto de las organizaciones enemigas de la reacción rebelde: la revolución que el grueso de la militancia confederal anhelaba y vislumbraba en sus mentes en líneas generales, debía posponerse a un futuro incierto, en otras condiciones mucho más factibles y prometedoras. El presente se encontraba atado de pies y manos por la urgente necesidad de parar a la reacción en todos los frentes -exteriores e interiores-y de conseguir la no paralización de toda la actividad economica. Lo que estaba en juego no era la posibilidad de hacer o no la revolución, sino algo mucho menos etéreo: lo que estaba en juego era, simple y llanamente, la supervivencia... incluida la de la propia CNT, algo que para muchos de los militantes tenía un valor superior al de sí mismos.

La coalición de la izquierda catalana llevaba desde antes de octubre de 1934 protagonizando un esfuerzo unitario antifascista al que únicamente faltaba añadir la aportación del anarcosindicalismo. El alzamiento trajo consigo dicho acercamiento forzoso entre todos los sectores antifascistas, el nacimiento de un régimen cuya finalidad no era otra que ganar la guerra.

Para analizar la actividad política confederal en los municipios, derivada de la coalición militar inicial forjada en los hechos del 19 de julio, podemos diferenciar dos etapas. Por un lado, la que se da al comienzo de la guerra y se extiende hasta finales de septiembre de 1936 - cuando se forma el tercer gobierno autonómico catalán de guerra, en el que se incluye a los libertarios- $y$, por otro, la que tiene lugar desde entonces hasta el final de la contienda civil, con la ocupación militar, el 26 de enero de 1939. 


\section{VERANO DE 1936: INICIO DE LA COALICIÓN POLÍTICO-MILITAR ANTIFASCISTA}

Respecto a la primera de ellas, el protagonismo político que ejerció la militancia libertaria del Vallès Occidental no vino determinado por su propia implantación en la comarca en dicho momento histórico y por sus propias iniciativas, por su situación hegemónica o no sobre el resto de las fuerzas políticas y sindicales enemigas del movimiento rebelde, sino por la actitud que adoptaron la mayor parte de los líderes confederales en la capital catalana con respecto a su relación con la coalición de izquierdas en la lucha militar contra el enemigo común, tanto para controlar de inmediato cualquier tipo de oposición interior dentro del territorio catalán como para luchar en los frentes de combate: al inclinarse por la colaboración total en la lucha contra el movimiento reaccionario, los militantes libertarios quedan también unidos a las restantes fuerzas antifascistas de cada localidad, llevando a cabo una actividad que se complementa a la del poder político institucional local ya existente y que ahora, tras el Decreto del Gobierno catalán de fecha 22 de julio, ha quedado limpio de toda presencia de la oposición derechista ${ }^{1}$.

La militancia libertaria asiste a reuniones en las que el nuevo poder político local constituido (controlado masivamente por los representantes de Esquerra Republicana de Catalunya) y las otras fuerzas de izquierda existentes en cada localidad, coordinan y unen sus fuerzas en la lucha militar contra el enemigo común, contra todos aquellos que pueden considerarse como aliados o amigos de la rebeldes. La primera intención será la de vencer la insurrección reaccionaria fascista; posteriormente, mantener el control sobre la población de la retaguardia y llevar a cabo el alistamiento de milicianos (es decir, hacer una milicia, un nuevo ejército) con destino a los frentes de combate.

Los organismos unitarios en cuestión son llamados Comités de Defensa o Comités de Milicias Antifascistas y su necesidad es palpable en las primeras semanas para evitar la posible involución de la situación y garantizar el nuevo régimen jurídico-político que ha nacido desde la insurrección fallida. Considerados como organismos unitarios locales de mando sobre los milicianos de la retaguardia, encuadrados en el Departamento de Defensa de la Generalitat de Catalunya, sus integrantes pasan a

Complementado con una Orden-Circular del Consejero de Gobernación de la misma fecha. Ambas normas fueron publicadas en el Butlletí Oficial de la Generalitat de Catalunya núm. 206, de 24-07-36 (Arxiu Nacional de Catalunya). 
recibir un salario proveniente del Gobierno catalán, que es pagado a través de los respectivos Ayuntamientos y a cuyo frente se encuentran los Alcaldes, que tienen asumida - ya antes de la guerra - la competencia de Delegados de Orden Público de la Generalitat, teniendo bajo su mando a todas las fuerzas de Orden Público existentes en su localidad respectiva.

La constitución de los mismos, como organismos unitarios de carácter básicamente militar y en los que están representadas todas las fuerzas antifascistas de cada localidad, no significa la existencia a partir de entonces de organismos antagónicos con respecto a los Ayuntamientos respectivos, en los que no hay ya ningún concejal de la oposición política: la legalidad de la existencia y actuación de dichos Comités viene dada por normas jurídicas que dicta el Gobierno catalán ?.

Sirva como ejemplo el caso de la ciudad industrial de Terrassa: desde la noche del sábado día 18 de julio, el Comité de Enlace Antifascista había estado reunido en sesión permanente con todas las autoridades locales en una de las dependencias del Ayuntamiento, para seguir de cerca todos los movimientos y acciones de lo que la prensa calificó como «elementos derechistas y desafectos a las autoridades populares». En dicho Comité de Enlace Antifascista figuraban Esquerra Republicana de Catalunya, Estat Català, Partit Comunista de Catalunya, Joventuts Socialistes Unificades, POUM, Unión Local de Sindicatos Obreros (ULSO, controlada por el POUM), UGT, PSOE, L!nió de Rabassaires, Centre Catalanista Republicà, Fraternitat Republicana Federal, CNT y FAI. El Comité Local Antifascista se constituirá al comienzo del mes de agosto, tras una reunión previa de todas las organizaciones antifascistas y de acuerdo con las instrucciones recibidas de la Comisión de Milicias Comarcales del Comité Central de Milicias Antifascistas, en las que se hacía saber que «únicamente reconocerá la personalidad de los Comités Locales o Comarcales constituidos con las distintas representaciones de las diferentes organizaciones antifascistas de las respectivas localidades». Quedó constituido con una representación de todas ellas, en el que el sector de ERC y similar tuvo 7 representantes, el sector marxista 6 (siendo 4 de ellos poumistas) y los libertarios $7^{3}$.

Los Ayuntamientos siguen realizando durante dicho verano su actividad normal rutinaria, con más o menos intensidad, además de atender las peticiones concretas que les remite el Comité de la localidad respectiva para poder realizar su misión de forma satisfactoria.

2 Decretos de 21, 23 y 24 de julio y Orden-Circular del Consejero de Gobernación de fecha 25 del mismo mes (BOGC núms. 203, 207 y 208, de los dias 21, 25 y 26-07-36).

3 L'Acció, núms. 8525 y 8534, de 23-07-36 y 2-08-36 (Arxiu Històric Comarcal de Terrassa). 
Cualquier enfoque idealizado o novelesco de los hechos ocurridos en las localidades vallesanas durante el verano de 1936, tiene que ser tildado de falta de seriedad y rigor, como mínimo. Antes al contrario: se trata de una lucha político-militar contra el enemigo común, que se identifica con la derecha en general, partidos, asociaciones e individualidades colaboradoras, simpatizantes y afines... Desde el poder político ya existente, ampliada su base participativa, consolidado por toda la izquierda catalana, eliminada la oposición, se usan todos los resortes del mismo para acabar con dicho enemigo... un enemigo que se encuentra dentro de todas y cada una de las localidades catalanas.

$Y$ como ocurre en cualquier guerra entre vecinos, las primeras medidas en tomarse van destinadas no sólo a la expulsión automática del seno de los Ayuntamientos de todos aquellos a los que se considera enemigos, así como a la incautación de bienes de los mismos, sino, además, a su detención o, incluso, a su aniquilamiento físico. En dichas actividades represivas colaborarán Comités y Ayuntamientos, encargándose básicamente éstos - su personal- de la labor de burocracia administrativa que ello genera ${ }^{4}$.

La CNT vallesana es una fuerza político-militar más de las que integran dichos Comités. Incluso hay localidades en las que no está integrada en los mismos, por la sencilla razón de que no hay allí constituido aún ningún sindicato confederal. $Y$ es que no son el producto de la iniciativa en solitario de la CNT y mucho menos de la iniciativa conjunta previa de la CNT y el POUM: en la mayor parte de los casos, las reuniones para su constitución se llevan a cabo en los edificios de los Ayuntamientos y bajo los auspicios del Alcalde, quien tiene bajo su autoridad a todas las fuerzas de Orden Público existentes en la localidad, además de la propia policía municipal. Se forman Comités de Defensa o Antifascistas en todas las localidades catalanas donde hay organizaciones antifascistas, con independencia de si hay o no presencia libertaria ${ }^{5}$.

Para los libertarios vallesanos, la integración en dichos Comités les permite el acceso a parte de los bienes inmuebles incautados y a que el resto de las organizaciones antifascistas les tengan que tener en cuenta

4 Decretos de 23 de julio (BOGC núm. 206, de 24-07-36) y de 5 de agosto (BOGC núm. 220, de 7-08-36).

5 Es el caso de Polinyà: Diari Oficial de la Generalitat de Catalunya núms. 269 y 290, de 2509-36 y 16-10-36. También, Arxiu Nacional de Catalunya, fondo Generalitat de Catalunya 19311939 (originales en Archivo Histórico Nacional-Sección Guerra Civil, Salamanca), caja o legajo 214, expediente 2, núms. 108-113. Vease también el caso de Llavorsí: ANC, fondo citado, caja 11, expediente 4, carta a Joan Casanovas, de fecha 11-09-36. 
en adelante para todo tipo de cuestiones que se planteen en la localidad, pero, a su vez, formar parte de la coalición en el poder les supone tener que comprometerse en el esfuerzo común de conseguir la vuelta a la normalidad de la vida cotidiana de la población en general, de contribuir a dicho fin de una manera efectiva para asegurar así la continuidad de la actividad económica y social de la retaguardia, además de proporcionar gran cantidad de milicianos, tanto para el control de la retaguardia como para el combate en los frentes de batalla.

También ocurre que la sindicalización generalizada de toda la población activa facilitará la necesidad de constituir organismos conjuntos con la UGT y la UR, dada la pluralidad sindical existente. Y las organizaciones libertarias locales verán supeditadas sus iniciativas, en general, a las decisiones de ámbito territorial catalán que se adopten en los diferentes Departamentos de la Generalitat de Catalunya, en Barcelona, en los que ya hay situados -en siete de ellos- representantes de la Confederación ${ }^{6}$.

\section{CONSOLIDACIÓN, DESARROLLO Y CAÍDA DEL NUEVO RÉGIMEN}

En lo que respecta a la segunda etapa, el protagonismo político de los representantes cenetistas se encuentra también supeditado a las decisiones que se adoptan por el Gobierno catalán en respecto a las Corporaciones Locales. Así, se establece qué organizaciones antifascistas tienen derecho a tener concejales - a estar representados en los Ayuntamientos- y qué número de representantes tendrá cada una de ellas. La participación política de los ciudadanos en sus Consistorios ya no será por medio de representes elegidos en las urnas, sino que serán las propias organizaciones antifascistas que cita la normativa jurídico-política las que designen a sus representantes: sólo las citadas por las normas serán las que tengan derecho a ello, sólo las que quiera el Gobierno catalán que se encuentren presentes en los mismos. El poder político institucional local catalán depende de la voluntad política del Consejo Ejecutivo de la Generalitat.

La consideración de que ha llegado el momento de avanzar rápidamente hacia la normalización y consolidación del nuevo régimen en todos los ámbitos de la vida cotidiana catalana, lleva al nuevo Consejo Ejecutivo unitario, en el que ya están los libertarios, a dictar, a los pocos días de

\footnotetext{
6 En concreto, en los Departamentos de Defensa, Economía y Servicios Públicos, Sanidad, Cultura, Trabajo, Obras Públicas y Justicia.
} 
constituirse, el Decreto de 9 de octubre de 1936, cuyo objetivo es simplificar y racionalizar la vida orgánica institucional local, suprimiendo los Comités y ordenando la constitución de nuevos Ayuntamientos, los segundos Ayuntamientos de guerra, cuya composición será similar a la del propio gobierno. La CNT -y a través de ella, indirectamente, el resto de las organizaciones libertarias - comienza una nueva andadura: tendrá que ocuparse de la gestión pública de los asuntos generales de todos los vecinos de cada localidad, no gobernando los municipios en solitario sino en gobiernos unitarios, colaborando codo con codo con el resto de las fuerzas de izquierda, sin apenas recursos económicos de los cuales poder disponer, en situación de guerra civil y - algo que a nosotros nos interesa resaltar- dentro del ámbito de competencias que la Generalitat permita en cada momento a los Ayuntamientos, dentro de las limitaciones legales que considere oportunas. Se trata, pues, de una nueva ocupación, muy diferente a la que los militantes confederales habían llevado a cabo hasta ese momento?.

Al igual que ocurría en la primera y breve etapa del comienzo de la guerra, los militantes libertarios vallesanos - como el resto de los catalanes - se encontrarán supeditados o delimitados en cuanto a su posible protagonismo o libertad de actuación a aquellas decisiones que se adopten en la capital catalana, al gobierno autonómico y a los líderes confederales. Ahora bien, cada uno de los grupos municipales cenetistas tendrá una dinámica política propia en sus respectivos Ayuntamientos, un protagonismo propio dentro de las limitaciones citadas, lo que requiere un estudio individualizado - al igual que ocurre en los Ayuntamientos actuales- de dicha participación a lo largo de todos los meses de la guerra.

Dicho protagonismo político local deriva de la presencia de concejales que representan a la CNT, de la participación política concreta en cada uno de dichos Ayuntamientos. Como regla general, podemos concluir que la CNT se encuentra presente en todos los municipios, que está representada en todos sus Ayuntamientos respectivos. Y aún cuando la Confederación ya no tendrá representantes en el gobierno catalán desde junio de 1937 y deberá limitarse a ocupar otro tipo de cargos en el organigrama de la Administración de la Generalitat, sin embargo, sí que tendrán derecho - hasta el final de la guerra- los Sindicatos Locales o las Federaciones Locales de Sindicatos cenetistas a nombrar a sus representantes en

7 Diari Oficial de la Generalitat de Catalunya núm. 285, de 11-10-36. Fue desarrollado por la Orden del Departamento de Seguridad Interior de fecha 12 de octubre (DOGC núm. 288, de 1410-36) (ANC). 
las Corporaciones Locales. Por lo tanto, la Confederación será, a lo largo de todo el conflicto bélico civil, partícipe del poder político que tiene la coalición catalana de izquierdas y su labor de colaboración en el mantenimiento de la actividad productiva, del control de la vida cotidiana de la retaguardia y del sostenimiento de los frentes de batalla, será siempre algo del máximo interés y necesidad para el nuevo régimen ${ }^{8}$.

Sin organizaciones locales confederales antes del conflicto en los pueblos con menos de $1.000 \mathrm{~h}$, básicamente agrícolas, la actividad militante desplegada tras el 19 de julio permitió la constitución de Sindicatos de Campesinos - de tan sólo algunas decenas de afiliados- en la práctica totalidad de los mismos, con su correspondiente representación en los Ayuntamientos respectivos. No obstante, dicha presencia institucional sería cada vez menor a lo largo del transcurso de la contienda, como la del resto de las organizaciones representadas. La actividad de dichos Consistorios será míniina.

En el resto de los municipios, la CNT está presente en todos ellos y sus representantes son partícipes del poder institucional local de una manera permanente, continuada, a lo largo de toda la guerra. La única excepción a dicha normalidad general vendrá dada por el Ayuntamiento de Sabadell, en el que la animadversión existente entre los líderes del PSUC/UGT hacia los maximalistas confederales con los que unos años atrás tuvieron graves enfrentamientos personales a causa de la escisión sindical, provocará, finalmente, la salida forzada de la CNT del Consistorio tras los Hechos de Mayo de 1937 en Barcelona, sin que se les deje volver a tener posteriormente representación en el mismo ${ }^{9}$.

\section{POSICIONAMIENTO Y RESPONSABILIDADES POLÍTICAS ANARCOSINDICALISTAS}

En las relaciones políticas mantenidas por la CNT con el resto de las organizaciones partícipes del poder local institucional (ERC, ACR, UR,

- Para una consulta detallada de cada uno de los veintidós municipios vallesanos y el conocimiento de las fuentes empleadas, véase mi tesis doctoral, inédita, Actividad política de la izquierda libertaria en la comarca del Vallès Occidental durante la guerra civil. Tras ser dirigida por Angeles Egido León (Departamento de Historia Contemporánea de la UNED), fue defendida el 6 de noviembre de 2001. El tribunal estuvo formado por Javier Tusell, Isidro Sepúlveda, Javier Paniagua, Mercedes Vilanova y Pere Gabriel.

9 Superación. Órgano de la CNT-FAl de Sabadell y su comarca, núms. 7 (de 12-03-37) y 8 (de 19-03-37). También, acta del pleno del Ayuntamiento de Sabadell celebrado el sábado 22 de mayo de 1937 (Arxiu Històric de Sabadell). 
UGT/PSUC y POUM), la trayectoria que sigue la Confederación en cada Ayuntamiento es peculiar e independiente de la queda seguir en los demás, pero sí podemos extraer la conclusión general —salvo algunas excepciones que confirman la regla- de que la mayor parte de la población vallesana tiene unos Ayuntamientos gobernados por equipos de gobierno en los que se integran todas las organizaciones que tienen delegación local en los respectivos municipios, incluyendo a la CNT: gobiernos unitarios donde las diferentes Regidurías o Comisiones se encuentran repartidas entre todas ellas. Unas relaciones de colaboración total y no de exclusiones.

Y es que, salvo el caso ya citado de Sabadell, hubo pocas confrontaciones periódicas y luchas internas por el poder. La consecuencia era la exclusión temporal del respectivo equipo de gobierno. Dichas exclusiones temporales las padecieron todas las organizaciones en mayor o menor medida. La CNT tan sólo fue excluida en los equipos de gobierno de cuatro municipios pequeños, mientras que fue mucho más perjudicada ERC, principalmente desde octubre de 1937 hasta el final de la guerra, como consecuencia de pactos entre el PSUC y la CNT.

Podemos concluir que la CNT no puede considerarse una víctima de la exclusión ejercida contra ella por parte del resto de las organizaciones de la coalición, que no puede hablarse de una situación de rechazo específico de los libertarios vallesanos. Antes bien, sí podemos hablar de una aceptación generalizada hacia los concejales confederales por parte de s!ıs compañeros en los Consistorios.

Un ejemplo de caso contrario al de la CNT es el protagonizado por el minoritario POUM: no sólo no tiene presencia orgánica en diez localidades vallesanas y ello le impide formar parte de dichos Ayuntamientos, sino que en Sabadell será excluido del equipo de gobierno desde el mismo momento de la constitución del Ayuntamiento (mientras que la CNT ocupa cuatro Regidurías) y en Terrassa también quedará excluido del equipo de gobierno local desde enero de 1937 por acuerdo expreso firmado por todas las restantes organizaciones, incluida la CNT ${ }^{10}$.

En cuanto al poder político municipal de la CNT en el Vallès Occidental, podernos distinguir tres etapas claramente diferenciadas:

A) La que va desde el comienzo del conflicto hasta la constitución de los segundos Ayuntamientos de la guerra, en octubre de 1936.

10 Acta del Pleno del Ayuntamiento de Terrassa celebrado el día 4 de enero de 1937 (Archivo del Ayuntamiento de Terrassa). 
B) La que va desde dicha constitución hasta octubre de 1937, tras la nueva normativa reguladora dictada por el gobierno autonómico.

C) La que va desde entonces hasta el final de la guerra, con la ocupación militar, el 26 de enero de 1939.

En la primera etapa, la izquierda libertaria vallesana se integra en los Comités Locales de Defensa o de Milicias Antifascistas -al igual que ocurre con el resto de las organizaciones antifascistas de cada localidad-y algunos de sus representantes ocupan parte de los cargos de responsabilidad y de mando que se crean. No obstante, los gobiernos locales siguen estando en los Ayuntamientos, al menos, legalmente.

En la segunda etapa se dan, primero, la participación cenetista en los gobiernos central y autonómico y, segundo, los Hechos de Mayo de 1937 en Barcelona y la falta de habilidad política posterior de la CNT para estar siquiera mínimamente representada en alguno de los dos. No obstante, al mismo tiempo, se trata de una etapa que permite a la Organización un avance muy rápido en la eficacia organizativa interna, en la constitución de nuevas estructuras sindicales, un mejor control de la militancia y una sólida experiencia en materia económica, política y militar. Puede decirse que cuando se llega a la segunda mitad del año 1937, la izquierda libertaria culmina su propio proceso evolutivo, tras tener que emprender una dura etapa de aprendizaje sobre cómo afrontar la realidad que le rodea.

En el Vallès Occidental la evolución es —en general- similar: si en octubre de 1936 tiene cinco Alcaldes y forma parte de los equipos de gobierno de los Ayuntamientos de todos los municipios que tienen más de 1.000 habitantes, en febrero del año siguiente llega a tener ocho Alcaldes y se mantiene en los mismos equipos de gobierno municipal. Sin embargo, en el verano de 1937 vuelve a bajar a cinco Alcaldes, se ha visto forzada a retirar su presencia de dos Ayuntamientos (entre ellos, el de la ciudad de Sabadell) y es excluida del equipo de gobierno de otro. Ahora bien, se ha consolidado la estructura sindical y el control de la vida económica de la comarca -en colaboración conjunia con la UGT- y ya tiene mucha más experiencia en todos los ámbitos, incluyendo el político.

Finalmente, la tercera etapa comienza con la constitución de los nuevos Ayuntamientos catalanes, los terceros desde el comienzo del conflicto bélico, de los que queda excluido el POUM y en los que el PSUC tiene la misma representación que ERC y CNT. Además, el Decreto de 8 de octubre de 1937 establece una diferencia importante con respecto a los anteriores Consistorios: todo puesto de concejal que quede vacante - -por falta de presencia de delegación local de la organización de que se trate o por ausencia injustificada durante un determinado plazo de tiempo- podrá 
ser ocupado por un representante de cualquiera de las organizaciones presentes en la Corporación ${ }^{11}$.

Aunque la CNT no ocupará ninguna cartera ministerial hasta abril de 1938 ni tampoco la titularidad de ninguna Consellería del Gobierno catalán, sí que tendrá representantes suyos ocupando cargos públicos en organismos fundamentales de ambas Administraciones y la unidad antifascista se irá estrechando con nuevos pactos entre los comunistas y la Confederación, simultáneamente a las derrotas militares y al aumento progresivo de los problemas de todo tipo en la vida cotidiana de la población de la retaguardia, a la que se van añadiendo cada vez más contingentes de refugiados procedentes de los diferentes frentes de combate.

Es en esas trágicas circunstancias, en dicha realidad circundante, en las que la CNT llega a un período evolutivo en el que apuesta abiertamente por la lucha política. En el Vallès Occidental ello le supone obtener nada menos que las cuatro Alcaldías de las localidades más importantes de la comarca (exceptuando Sabadell), gracias a una alianza política con el PSUC, en detrimento de ERC. Pero no son casos aislados Terrassa, Rubí, Sant Cugat del Vallès y Montcada i Reixac, sino que los datos indican una aumento progresivo en el número de Alcaldes: si en octubre de 1937 únicamente tiene cuatro Alcaldes, ya son seis en febrero de 1938, se mantiene el mismo número en junio y sube a siete en octubre. Todo ello a pesar de que ya hay tres Ayuntamientos gestionados por la Dirección General de Administración Local.

Además, los representantes confederales forman parte de los equipos de gobierno de la casi absoluta totalidad de los Ayuntamientos de las localidades de la comarca con más de 1.000 habitantes.

Por tanto, la última etapa de la guerra viene marcada por una hegemonía política de la CNT y el PSUC, en detrimento de ERC, una hegemonía que es también el reflejo de lo que ocurre en el ámbito socio-económico cotidiano, en el que la CNT y la UGT han ido progresivamente constituyendo y consolidando múltiples organismos unitarios de actuación conjunta, incluso en Sabadell.

11 DOGC núm. 283, de 10-10-37. 